\title{
Influence of multiple stapler firings used for rectal division on colorectal anastomotic leak rate
}

\author{
Tamara Braunschmid ${ }^{1}$ Nikolaus Hartig ${ }^{2} \cdot$ Lukas Baumann $^{4} \cdot$ Bernhard Dauser $^{2}$ • \\ Friedrich Herbst ${ }^{2,3}$
}

Received: 21 January 2017 / Accepted: 16 May 2017/Published online: 20 June 2017

(C) The Author(s) 2017. This article is an open access publication

\begin{abstract}
Background Anastomotic leakage following colorectal resection remains one of the most significant complications with relevant morbidity and mortality. There is evidence that a higher number of stapler firings for rectal division can affect the leak rate in double stapling anastomosis. However, there are no data concerning compression anastomosis. We present our institutional experience addressing this issue.

Design This is a retrospective review of a prospective institutional database of patients undergoing colonic and rectal resection for benign and malignant indications between January 2008 and December 2014 at the surgical department of the St. John of God Hospital, Vienna. Inclusion criteria were rectal division with linear stapling devices and construction of anastomosis to the rectal stump using a circular stapler or compression device.

Results Three hundred eighty two (196 female; 51.3\%) patients were included. Mean age was 65.8 years (range: 18-95) Indications for the operation included diverticular disease (44.8\%), colorectal carcinoma (51.6\%),
\end{abstract}

This study has been presented at the Austrian Surgical Congress, 2015 (Linz, Austria) and at the German Surgical Congress, 2016 (Berlin, Germany).

Tamara Braunschmid

tamara.braunschmid@meduniwien.ac.at

1 Department of Surgery, Medical University of Vienna, Spitalgasse 23, 1090 Vienna, Austria

2 Department of Surgery, St. John of God Hospital, Vienna, Austria

3 Medical Faculty, Sigmund Freud University, Vienna, Austria

4 Center for Medical Statistics, Informatics and Intelligent Systems, Medical University of Vienna, Vienna, Austria inflammatory bowel disease (1.8\%), and adenoma (1.8\%). A laparoscopic approach was employed in 334 cases (87.4\%); in 170 patients $(44.9 \%)$, a compression anastomosis was created. One, two, and three or more stapler cartridges were used for rectal division in 58.4, 33.5, and $8.1 \%$, respectively. Male gender, neoadjuvant therapy, rectal cancer as an underlying disease, laparoscopic surgical approach, and duration of operation longer than $200 \mathrm{~min}$ are leading causes for the usage of more than one stapler cartridge. Overall leak rate was $4.7 \%$ (18/382). The only factor associated with the occurrence of leakage was the use of three or more stapler cartridges for the closure of the rectal stump ( $p=0.002$ ).

Conclusion Our data support that multiple stapler firings for rectal division following colorectal resection has a major impact on anastomotic leak rate. Especially in laparoscopic surgery efforts should be made to minimize the number of stapler cartridges used.

Keywords Multiple stapler firings - Anastomotic leakage · Compression anastomosis - Stapler anastomosis - Rectal division $\cdot$ Colorectal diseases

Anastomotic leakage represents one of the most severe complications after formation of a colorectal anastomosis, with relevant morbidity and mortality. In general, anastomotic leak rates range between 3.2 and 36\% [1-9].

The basic requirements for anastomotic healing are an appropriate blood supply, healthy bowel ends, and a tension-free anastomosis [10-12].

Many studies have explored multiple variables in order to define their extent of influence on anastomotic leakage. Recent studies reported BMI to be an independent risk factor for the increase in anastomotic leak rate [13]. 
Besides, also the classification of the American Society of Anesthesiologists (ASA) seems to be an important factor because patients with higher ASA-scores also have a higher occurrence of anastomotic leaks [14]. Furthermore, the duration of operation, which often represents the complexity of an individual surgical procedure, seems to have an influence on anastomotic safety [3, 14]. Both, an inflamed bowel seen in acute diverticulitis or inflammatory bowel disease as well as previously irradiated bowel because of radio-chemotherapy can represent a difficult environment for the creation of a safe colorectal anastomosis [4, 15]. However, the most critical factor regarding anastomotic leaks is the level of the anastomosis, which seems to have a severe impact on the leakage rate, regardless of an open or laparoscopic approach [1-4, 16, 17]. Leak rates are higher following low anterior resection, no matter which technique was used [2, 16-18]. Particularly in laparoscopic colectomy, the narrow confines of the pelvis often results in an unideal cutting angle, leading to the use of more than one stapler cartridge for rectal division [2-4].

Several studies demonstrated the influence of multiple stapler firings on anastomotic leak rate [2-4]. However, there are no studies discussing the influence of multiple stapler firings on the safety of compression anastomoses.

The aim of the study is to present our institutional experience concerning anastomotic safety.

\section{Materials and methods}

\section{Patient selection and surgical procedures}

A retrospective analysis of a prospectively maintained institutional database of all colorectal resections, performed between November 2008 and December 2014, was carried out. We only included cases in which a colorectal anastomosis was performed after rectal transection with linear staplers. Anastomosis was created with a circular stapling or compression device (ColonRing ${ }^{\circledR}$, NovoGI LTD., Netanya, Israel). Out of 827 patients gathered in the database, 382 patients fulfilled the inclusion criteria. The indications for an operation included colorectal carcinoma or adenoma, inflammatory bowel disease, or diverticular disease. Whenever a diverting stoma was planned, patients received preoperative bowel preparation with three liters of polyethylene glycol solution on the day before the operation. The remaining patients received a rectal enema only. The BMI was defined according to the definitions of the World Health Organization (WHO) [19, 20].

All anastomoses were created intracorporeally. The closure of the rectal stump was performed using one or more firings of a linear stapling device. Thereafter, colorectal anastomosis was done using a circular stapling device or a compression anastomotic device. The anastomotic integrity was checked by the inspection of the doughnuts and insufflation of air.

From January 2009 onwards, for construction of rectal anastomosis, a compression anastomotic device was used exclusively by two members of staff. This was part of a prospective evaluation of this new technology and was registered with https://ClinicalTrials.gov under NCT01056913.

Anastomotic leakage was defined as proposed by Rahbari et al. [8]. A computed tomography was not done routinely in patients that received an anastomosis. Nevertheless, if there were any clinical suspicions of a leakage, a computed tomography was done to verify or falsify the assumptions.

The primary endpoint of this retrospective survey was the occurrence of an anastomotic leak.

\section{Statistical analyses}

The statistical analysis was performed using $\mathrm{R}$ version 3.3.0. All variables were categorized. The univariate associations were tested with Chi-Square Tests or-if assumptions were not met-Fisher's Exact Tests. As this is an exploratory study we did not correct for multiple testing. $p<0.05$ was considered significant for all tests. To analyze the multivariate impact of independent variables on the number of stapler cartridges used, a multivariate logistic regression model was conducted. Therefore, the number of cartridges was dichotomized (1 vs. 2 or more cartridges). All variables were included in the first model, and a stepwise selection with the Akaike Information Criterion (AIC) was performed to find the most influential variables. A multivariate model for the risk of anastomotic leakage was planned but as only one variable showed a univariate association, this model was not computed.

\section{Institutional review board}

The study protocol was approved by the local ethics committee.

\section{Results}

The study population of 382 patients included $186(48.7 \%)$ men and 196 (51.3\%) women. Mean age at operation was 65.8 years (range: 18-95 years). Fifty point five percent of the patients were older than 65 years. The mean Body Mass Index (BMI) within the cohort was 25.91 (range 15.1-55.4). Demographic data are shown in Table 1. 
Table 1 Demographic data; $n=382$

\begin{tabular}{|c|c|}
\hline Variable & $n(\%)$ \\
\hline \multicolumn{2}{|l|}{ Sex } \\
\hline Male & $186(48.7)$ \\
\hline Female & $196(51.3)$ \\
\hline \multicolumn{2}{|l|}{ BMI } \\
\hline Underweight & $11(2.9)$ \\
\hline Normal & $150(39.3)$ \\
\hline Overweight & $155(40.6)$ \\
\hline Obesity & $66(17.3)$ \\
\hline \multicolumn{2}{|l|}{ ASA } \\
\hline I & $209(54.7)$ \\
\hline II & $121(31.7)$ \\
\hline III & $48(12.6)$ \\
\hline IV & $4(1.0)$ \\
\hline \multicolumn{2}{|l|}{ Age at surgery (years) } \\
\hline$<50$ & $47(12.3)$ \\
\hline $50-64.9$ & $136(35.6)$ \\
\hline $65-74.9$ & $126(33.0)$ \\
\hline$\geq 75$ & $73(19.1)$ \\
\hline \multicolumn{2}{|l|}{ Diagnosis } \\
\hline Rectal cancer & $97(25.4)$ \\
\hline Colon cancer & $99(25.9)$ \\
\hline Adenoma & $7(1.8)$ \\
\hline Diverticular disease & $172(45.0)$ \\
\hline Inflammatory bowel disease & $7(1.8)$ \\
\hline \multicolumn{2}{|l|}{ Surgical approach } \\
\hline Laparoscopically & $334(87.4)$ \\
\hline Open & $48(12.6)$ \\
\hline \multicolumn{2}{|l|}{ Type of operation } \\
\hline Sigmoid resection & $166(43.5)$ \\
\hline Left hemicolectomy & $74(19.4)$ \\
\hline Anterior resection & $57(14.9)$ \\
\hline Low anterior resection & $85(22.3)$ \\
\hline
\end{tabular}

Influence of multiple stapler firings used for rectal division on colorectal anastomotic leak rate

\section{Indications for operation}

Fifty-one point six percent of patients underwent resection for colorectal cancer, whereas $48.4 \%$ were treated because of a benign indication such as adenoma (1.8\%), diverticular $(44.8 \%)$ or inflammatory bowel disease $(1.8 \%)$.

Compared to benign indications, in cancer operations more often three or more stapler cartridges were used for the closure of the rectal stump (13.7 vs. $2.2 \% ; p<0.001$ ), anastomoses were constructed more frequently in the lower third of the rectum $(39.6$ vs. $2.7 \% ; p<0.001)$ and a protective stoma was created more often (33.5 vs. 2.7\%; $p<0.001)$.
Out of 97 cases with rectal cancer, 47 patients (48.5\%) received neoadjuvant chemoradiation $(n=22)$, shortcourse radiotherapy ( $25 \mathrm{~Gy} ; n=20$ ), or chemotherapy only $(n=5)$.

\section{Surgical procedures and related complications}

The majority of procedures $(87.4 \%)$ were performed laparoscopically. In $5.2 \%$, a conversion to the open technique was required. A primary open access was only used in patients who had already had multiple open abdominal surgeries. In $67.1 \%(57 / 85)$ of the patients who underwent a low anterior resection, a protective ileostomy was created.

Forty-three point five percent of patients underwent a sigmoid resection, $19.4 \%$ received a left hemicolectomy, in $14.9 \%$ a high anterior resection, and in $22.3 \%$ a low anterior resection was performed. In 225 cases (58.9\%), the anastomosis was located in the upper third of the rectum $(12-16 \mathrm{~cm})$, in $74(19.4 \%)$ it was located in the middle third $(7-11 \mathrm{~cm})$, and in $83(21.7 \%)$ it was located in the lower third ( $6 \mathrm{~cm}$ or lower). In $68.7 \%$ of all patients with anastomosis in the lower third, a diverting loop ileostomy was created.

In $58.4 \%(n=223)$ of all resections only one stapler cartridge was used to divide the rectum, whereas in $33.5 \%$ $(n=128)$ two magazines were used and in $8.1 \%(n=31)$ three or more magazines were required.

For the construction of the anastomosis, a circular stapler was used in $55.5 \% \quad(n=212)$, whereas $44.5 \%$ $(n=170)$ were performed with a compression anastomotic device. Within our cohort patients who received an anastomosis in the lower third (22.3\%) showed a significantly higher anastomotic leak rate without a difference between stapled and compression anastomosis. In general, patients who received a compression anastomosis had significantly lower anastomoses $(p<0.001)$ and therefore a higher protective stoma rate $(p<0.001)$.

All stomata were created as protective stomata. Three patients hat no reoperation because of an intermittently risen operation-risk or because of their individual decision to keep the stoma.

The average duration of the operation was $209 \mathrm{~min}$ (range: 45-630 $\mathrm{min}$ ). Within laparoscopic procedures the mean operation duration was $200 \mathrm{~min}$ (range: 45-630 $\mathrm{min}$ ), whereas within interventions in open technique, the mean operation duration was 194 min (range: 85-490 min).

The mean hospital stay was 9 days (range: $2-124$ days). There was a significant difference within the in-hospital stay regarding the surgical approach. Patients who underwent an open surgical procedure had significantly longer postoperative hospital stays than patients that received a 
laparoscopic procedure (13 vs. 8 days; $p=0.001)$. As expected, the development of an anastomotic leak led to a statistically significant prolongation of the hospital stay (27.5 days with vs. 8 days without leak; $p<0.001$ ).

\section{Preconditions affecting the number of stapler firings}

Within the univariate analysis-see Table 2, we found several factors that could possibly have an influence on the number of linear stapler firings used for rectal division. From the patients' preconditions gender, previous diagnosis and neoadjuvant therapy showed significant results. Regarding the surgical procedure itself, we found significant differences for the type of surgical approach, the type of operation, the level of anastomosis, the anastomotic technique, as well as for the duration of the operation. Multivariate analysis showed that male gender, rectal cancer as an underlying disease, neoadjuvant therapy, laparoscopic approach, and duration of operation longer than 200 min have the most relevant influence on the usage of more than one linear stapler magazine to divide the rectum.

\section{Anastomotic leakage}

Eighteen of the 382 patients (5.4\%, male $n=10)$ developed an anastomotic leak-see Table 3. Those patients' mean age was 61.5 years (range: $31-79$ years), the mean BMI was 26.9 (range: 19.1-55.4), the mean duration of the surgical intervention was $245 \mathrm{~min}$ (range: 141-490 min), and the mean postoperative in-hospital stay was 39.6 days (range: 9-115 days). In 7 patients (38.9\%), a stapling device was used to create the anastomosis, whereas 11 times $(61.1 \%)$ a compression device was utilized. To divide the rectum in 6 cases (33.3\%), one stapler cartridge was used, in 6 cases (33.3\%) two stapler cartridges were used, and in 6 cases $(33.3 \%)$, three up to six stapler cartridges were needed.

No patient in this group died. Regarding treatment of leaks only four anastomoses (22.2\%) could not be salvaged ( 2 open and 2 laparoscopic Hartmann's procedures). Eight patients underwent an abdominal revision with the creation of an ileostomy (4 open, 4 laparoscopic), and one underwent laparotomy with redo of the anastomosis (ileostomy already present). Three patients received a transanal endoscopic vacuum therapy (one needed additional laparotomy and lavage for persistent peritonitis). Two patients with ultralow compression anastomosis and a protective ileostomy already in place underwent a transanal removal of the device and repair of the anastomosis.

All salvaged anastomoses healed and the stomata were closed at a later stage. Only one patient in the Hartmann group did not have the terminal colostomy reversed.
Interestingly, within univariate analysis, we could not find any patient-related risk factors such as age, BMI, or ASA ( $p=0.970, p=0.100$ ) having a significant influence on the leak rate. Not even technical factors such as surgical approach, type of operation, anastomotic height, or anastomotic technique seemed to have an influence on anastomotic safety $(p=1.000, \quad p=0.121, \quad p=0.204$, $p=0.226$ ). The only variable showing a significant influence on the development of an anastomotic leak was the number of linear stapler firings that have been used for rectal division $(p=0.002)$.

\section{Discussion}

Anastomotic leakage remains one of the most serious complications after colorectal resection $[8,21]$. It increases morbidity and mortality as well as reoperation rate and hospital stay [7, 21]. In the past, many studies have tried to identify potential risk factors that favor the development of an anastomotic leak. [1-4, 14, 17].

Many risk factors were suspected to have an appreciable influence on the occurrence of anastomotic leaks. Often patients' preconditions such as age, gender, BMI, or ASA have been assumed to cause a higher risk for the integrity of an anastomosis [13, 14, 18, 22]. However, in our cohort, we were not able to demonstrate a correlation between patient characteristics and leak rate. Regarding literature, there is evidence that technical aspects have an even bigger influence on anastomotic safety than patient preconditions $[1,14]$. The anastomotic level as well as the number of linear stapler firings that are used for rectal division seems to have a major impact on the development of an anastomotic dehiscence [2-4, 16]. Previous studies have demonstrated the significance of the anastomotic level as an independent risk factor for anastomotic safety. [1, 3, 4]. Anyhow within our cohort, we could not confirm these findings.

Several studies have discussed the relationship between the number of stapler firings and the rate of anastomotic leaks. In 2008, Ito et al. demonstrated a significant relationship between the number of stapler cartridges used for rectal division and the occurrence of anastomotic leaks [2]. One year later, Kim and colleagues were able to validate these findings by their prospective study including 270 patients [3]. This report gave strong evidence that the application of multiple stapler cartridges and an anastomosis located in the middle or lower rectum are major contributors for development of an anastomotic leak [3]. Park et al. could also verify these findings in 2013 [4].

In our study, the number of stapler firings emerged to have the most powerful influence on the occurrence of anastomotic leaks. In contrast to many other studies, 
Table 2 Patient characteristics and number of stapler cartridges used for rectal transection

\begin{tabular}{|c|c|c|c|c|c|c|c|}
\hline \multirow[t]{2}{*}{ Variable } & \multirow{2}{*}{$\begin{array}{l}\text { Total no. of patients } \\
n=382\end{array}$} & \multicolumn{3}{|c|}{ Number of stapler cartridges } & \multirow[t]{2}{*}{$p$ value } & \multicolumn{2}{|c|}{ Multivariate analysis } \\
\hline & & $\begin{array}{l}1 \\
n=223(\%)\end{array}$ & $\begin{array}{l}2 \\
n=128(\%)\end{array}$ & $\begin{array}{l}\geq 3 \\
n=31(\%)\end{array}$ & & Odds ratio & CI $(95 \%)$ \\
\hline \multicolumn{8}{|l|}{ Sex } \\
\hline Male & 186 & $96(51.6)$ & $68(36.6)$ & $22(11.8)$ & 0.007 & 1.00 & - \\
\hline Female & 196 & $127(64.8)$ & $60(30.6)$ & $9(4.6)$ & & 0.69 & $0.43-1.11$ \\
\hline \multicolumn{8}{|l|}{ BMI } \\
\hline Underweight & 11 & 7 (63.6) & $4(36.4)$ & 0 & 0.957 & & \\
\hline Normal & 150 & $89(59.3)$ & $51(34.0)$ & $10(6.7)$ & & & \\
\hline Overweight & 155 & $88(56.8)$ & $52(33.5)$ & $15(9.7)$ & & & \\
\hline Obese & 66 & $39(59.1)$ & $21(31.8)$ & $6(9.1)$ & & & \\
\hline \multicolumn{8}{|l|}{ ASA } \\
\hline I & 209 & $121(57.9)$ & $71(34.0)$ & $17(8.1)$ & 0.627 & & \\
\hline II & 121 & $72(59.5)$ & $41(33.9)$ & $8(6.6)$ & & & \\
\hline III & 48 & $29(60.4)$ & $14(29.2)$ & $5(10.4)$ & & & \\
\hline IV & 4 & $1(25.0)$ & $2(50.0)$ & $1(25.0)$ & & & \\
\hline \multicolumn{8}{|l|}{ Age at surgery (years) } \\
\hline$<50$ & 47 & $27(57.4)$ & $16(34.0)$ & $4(8.5)$ & 0.727 & & \\
\hline $50-64.9$ & 136 & $74(54.4)$ & $48(35.3)$ & $14(10.3)$ & & & \\
\hline $65-74.9$ & 126 & $81(64.3)$ & $37(29.4)$ & $8(6.3)$ & & & \\
\hline$\geq 75$ & 73 & $41(56.2)$ & $27(37.0)$ & $5(6.8)$ & & & \\
\hline \multicolumn{8}{|l|}{ Underlying diagnosis } \\
\hline Benign & 185 & $127(68.6)$ & $54(29.2)$ & $4(2.2)$ & $<0.001$ & & \\
\hline Malignant & 197 & $96(48.7)$ & $74(57.8)$ & $27(13.7)$ & & & \\
\hline \multicolumn{8}{|l|}{ Diagnosis } \\
\hline Rectal cancer & 97 & $24(24.7)$ & $50(51.5)$ & $23(23.7)$ & $<0.001$ & 1.00 & - \\
\hline Colon cancer & 99 & $71(71.7)$ & $24(24.2)$ & $4(4.0)$ & & 0.19 & $0.09-0.38$ \\
\hline Adenoma & 7 & $3(42.9)$ & $4(57.1)$ & 0 & & 0.86 & $0.16-5.16$ \\
\hline Diverticular disease & 172 & $119(69.2)$ & $49(28.5)$ & $4(2.3)$ & & 0.20 & $0.10-0.39$ \\
\hline IBD & 7 & $6(85.7)$ & $1(14.3)$ & 0 & & 0.06 & $0.00-0.39$ \\
\hline \multicolumn{8}{|l|}{ Previous therapy } \\
\hline No & 335 & $212(63.3)$ & $109(32.5)$ & $14(4.2)$ & $<0.001$ & 1.00 & - \\
\hline Yes & 47 & $11(23.4)$ & $19(40.4)$ & $17(36.3)$ & & 2.36 & $0.93-6.37$ \\
\hline \multicolumn{8}{|l|}{ Surgical approach } \\
\hline Laparoscopic & 334 & $181(54.2)$ & $123(36.8)$ & $30(9.0)$ & $<0.001$ & 1.00 & - \\
\hline Open & 48 & $42(87.5)$ & $5(10.4)$ & $1(8.1)$ & & 0.11 & $0.03-0.27$ \\
\hline \multicolumn{8}{|l|}{ Type of operation } \\
\hline Sigmoid resection & 166 & $123(74.1)$ & $41(24.7)$ & $2(1.2)$ & $<0.001$ & & \\
\hline Left hemicolectomy & 74 & $48(64.9)$ & $23(31.3)$ & $3(4.1$ & & & \\
\hline Anterior resection & 57 & $30(52.6)$ & $22(38.6)$ & $5(8.8)$ & & & \\
\hline Low anterior resection & 85 & $22(25.9)$ & $42(24.7)$ & $21(24.7)$ & & & \\
\hline \multicolumn{8}{|l|}{ Anastomotic device } \\
\hline Stapler & 212 & $140(66.0)$ & $63(29.7)$ & $9(4.2)$ & $<0.001$ & & \\
\hline Compression & 170 & $83(48.8)$ & $65(38.2)$ & $22(12.9)$ & & & \\
\hline \multicolumn{8}{|l|}{ Anastomotic height } \\
\hline Low $(\leq 6 \mathrm{~cm})$ & 83 & $23(27.7)$ & $40(48.2)$ & $20(24.1)$ & $<0.001$ & & \\
\hline Middle $(>6-12 \mathrm{~cm})$ & 74 & $41(55.4)$ & $27(36.5)$ & $6(8.1)$ & & & \\
\hline High $(>12-16 \mathrm{~cm})$ & 225 & 159 (70.7) & $61(27.1)$ & $5(2.2)$ & & & \\
\hline Duration of operation & & & & & & & \\
\hline
\end{tabular}


Table 2 continued

\begin{tabular}{|c|c|c|c|c|c|c|c|}
\hline \multirow[t]{2}{*}{ Variable } & \multirow{2}{*}{$\begin{array}{l}\text { Total no. of patients } \\
n=382\end{array}$} & \multicolumn{3}{|c|}{ Number of stapler cartridges } & \multirow[t]{2}{*}{$p$ value } & \multicolumn{2}{|c|}{ Multivariate analysis } \\
\hline & & $\begin{array}{l}1 \\
n=223(\%)\end{array}$ & $\begin{array}{l}2 \\
n=128(\%)\end{array}$ & $\begin{array}{l}\geq 3 \\
n=31(\%)\end{array}$ & & Odds ratio & CI $(95 \%)$ \\
\hline$\leq 200 \min$ & 196 & $134(68.4)$ & $54(27.6)$ & $8(4.1)$ & $<0.001$ & 1.00 & - \\
\hline$>200 \min$ & 186 & $89(47.8)$ & $74(39.8)$ & $23(12.4)$ & & 1.92 & $1.20-3.10$ \\
\hline
\end{tabular}

Statistically significant $p$ values are given in bold

Highest values are given in italic

Influence of multiple stapler firings used for rectal division on colorectal anastomotic leak rate

Table 3 Patient characteristics and anastomotic leak rate

\begin{tabular}{|c|c|c|c|}
\hline Variable & Patients with anastomotic leak & Leakage $(\%)$ & $p$ value \\
\hline Global leak rate & $18 / 382$ & 4.7 & - \\
\hline \multicolumn{4}{|l|}{ Sex } \\
\hline Male & $10 / 186$ & 5.4 & \multirow[t]{2}{*}{0.722} \\
\hline Female & $8 / 196$ & 4.1 & \\
\hline \multicolumn{4}{|l|}{ BMI } \\
\hline Underweight & $0 / 11$ & - & \multirow[t]{4}{*}{0.970} \\
\hline Normal & $8 / 150$ & 5.3 & \\
\hline Overweight & $7 / 155$ & 4.5 & \\
\hline Obese & $3 / 66$ & 4.6 & \\
\hline \multicolumn{4}{|l|}{ ASA } \\
\hline I & $7 / 209$ & 3.4 & \multirow[t]{4}{*}{0.100} \\
\hline II & $6 / 121$ & 4.9 & \\
\hline III & $4 / 48$ & 8.3 & \\
\hline IV & $1 / 4$ & 25.0 & \\
\hline \multicolumn{4}{|l|}{ Age at surgery (years) } \\
\hline$<50$ & $3 / 47$ & 6.4 & \multirow[t]{4}{*}{0.894} \\
\hline $50-64.9$ & $7 / 136$ & 5.2 & \\
\hline $65-74.9$ & $5 / 126$ & 3.9 & \\
\hline$\geq 75$ & $3 / 73$ & 4.1 & \\
\hline \multicolumn{4}{|l|}{ Underlying diagnosis } \\
\hline Benign & $5 / 185$ & 2.7 & \multirow[t]{2}{*}{0.120} \\
\hline Malignant & $13 / 197$ & 6.6 & \\
\hline \multicolumn{4}{|l|}{ Diagnosis } \\
\hline Rectal cancer & $8 / 97$ & 8.3 & \multirow[t]{5}{*}{0.377} \\
\hline Colon cancer & $5 / 99$ & 5.1 & \\
\hline Adenoma & $0 / 7$ & - & \\
\hline Diverticular disease & $5 / 172$ & 2.9 & \\
\hline IBD & $0 / 7$ & - & \\
\hline \multicolumn{4}{|l|}{ Neoadjuvant therapy } \\
\hline No & $13 / 335$ & 3.9 & \multirow[t]{2}{*}{0.057} \\
\hline Yes & $5 / 47$ & 10.6 & \\
\hline \multicolumn{4}{|l|}{ Surgical approach } \\
\hline Laparoscopic & $16 / 334$ & 3.9 & \multirow[t]{2}{*}{1.000} \\
\hline Open & $2 / 48$ & 4.1 & \\
\hline \multicolumn{4}{|l|}{ Type of operation } \\
\hline Sigmoid resection & $7 / 166$ & 4.2 & \multirow[t]{2}{*}{0.121} \\
\hline Left hemicolectomy & $1 / 74$ & 1.4 & \\
\hline
\end{tabular}


Table 3 continued

\begin{tabular}{llll}
\hline Variable & Patients with anastomotic leak & Leakage $(\%)$ & $p$ value \\
\hline Anterior resection & $2 / 57$ & 3.5 & \\
Low anterior resection & $8 / 85$ & 9.4 & $\mathbf{0 . 0 0 2}$ \\
Number of cartridges & & 2.7 & \\
1 & $6 / 223$ & 4.7 & 0.226 \\
2 & $6 / 128$ & 19.4 & \\
$\geq 3$ & $6 / 31$ & 3.3 & 0.204 \\
Anastomotic device & & 6.5 & \\
Stapler & $7 / 212$ & & \\
Compression & $11 / 170$ & 8.4 & \\
Anastomotic height & & 2.7 & \\
Low $(\leq 6 \mathrm{~cm})$ & $7 / 83$ & 4.0 & \\
Middle $(>6-12 \mathrm{~cm})$ & $2 / 74$ & 4.1 & \\
High $(>12-16 \mathrm{~cm})$ & $9 / 225$ & 5.4 & \\
Duration of operation & & & \\
$\leq 200$ min & $8 / 196$ & $10 / 186$ &
\end{tabular}

Statistically significant $p$ value is given in bold

Influence of multiple stapler firings used for rectal division on colorectal anastomotic leak rate

anastomotic level was not significant. There may be two explanations for this discrepancy; on one hand three or more stapler magazines were predominantly used in the lower third, on the other hand the number of patients in our series could be too small.

There are several reasons as to why more than one stapler cartridge is needed to divide the large rectum. Firstly, the large diameter of the wall in the middle and lower rectum could be the reason to use more than one magazine [1-3]. Secondly, if initially a small magazine with $45 \mathrm{~mm}$ instead of $60 \mathrm{~mm}$ is used, there is a higher chance that in the end more than one magazine has to be applied to divert the large bowel [1]. Thirdly, the limited space and angle within the laparoscopic surgical approach as well as a narrow male pelvis is a risk factor that often leads to the usage of two or more magazines [1-3].

Also our study confirms these findings. Multivariate analysis showed that besides male gender also rectal cancer as an underlying disease as well as neoadjuvant therapy and laparoscopic procedure seemed to be a risk factor that more stapler cartridges are used.

In literature, it has been demonstrated that more stapler cartridges are also used in patients with a longer operation time [3]. Again, we could show this effect within our data. The usage of more stapler firings to divide the bowel is more likely in surgical interventions that are more complex and taking longer than $200 \mathrm{~min}$.

The viability of the bowel ends to be connected is an essential factor for anastomotic safety. In case of preoperative chemoradiation or in the event of inflammation of the bowel wall, the integrity of the tissue is not always guaranteed. For diverticulitis, the laparoscopic approach seems to have a positive effect concerning the risk of anastomotic leak [23]. Interestingly, in our study, we found a significantly lower stoma rate in patients with benign primary disease which seems to originate in the fact that patients with benign diseases have significantly higher anastomoses than patients with a malignant underlying disease.

According to the literature, anastomoses to the middle or low rectum are associated with a higher risk for anastomotic leakage $[1,3]$. As a consequence, the creation of a protecting stoma should be considered in high-risk patients particularly when they receive a very low anastomosis $[1,3,4,14,24,25]$.

Laparoscopic colectomy was first described in the literature in 1991 by Jacobs and colleagues [26]. Following this publication, numerous studies have evaluated the safety and feasibility of laparoscopic versus the open technique for colorectal resections under many different conditions. The most crucial points concerning laparoscopic colorectal resection were on the one hand the adequacy of the cancer operation in regard to free tumor margins and sufficient lymph node resection, and on the other hand the feasibility and safety for sphincter-preserving surgery of the low and middle rectum [25]. Many studies in the last two decades demonstrated that laparoscopic colorectal resections and open resections have comparable oncological and functional results [27-30]. The leak rates are similar, even in patients that underwent neoadjuvant radiotherapy [27]; the in-hospital stay was even shorter in laparoscopically operated patients [31, 32]. 
Our data confirm that a laparoscopic approach is neither followed by a higher leak rate nor by a longer in-hospital stay; in contrast, patients that underwent a laparoscopic surgical procedure had shorter postoperative in-hospital stays than those with an open surgical approach.

Comparing compression to stapled anastomoses, there were no significant differences regarding duration of operation, postoperative hospital stay, or anastomotic leak rate.

\section{Conclusion}

The occurrence of anastomotic leaks following colorectal resection is still one of the most serious complications. Our experience shows that patients' preconditions are not the most determining variables concerning anastomotic leaks. On the contrary, technical details within the operation have a decisive impact on anastomotic leakage. It can be said that the most important factor for anastomotic safety is the use of fewer stapler cartridges in colorectal anastomosis. If it is foreseeable that more than one stapler cartridge will be required for rectal division, the surgical approach should be reevaluated. Be it the placement of another trocar or a small laparotomy to finish the rectal division using a hand port, regardless, an adjustment to the surgical approach should be considered in order to minimize the number of stapler cartridges used.

Funding Open access funding provided by Medical University of Vienna. There were no sources of financial support, corporate involvement, patent holdings, etc. involved in the research and preparation of this manuscript.

\section{Compliance with ethical standards}

Disclosure Drs. Braunschmid, Hartig, Dauser, Herbst, and Mr. Baumann have no conflict of interest or financial ties to disclose.

Open Access This article is distributed under the terms of the Creative Commons Attribution 4.0 International License (http://crea tivecommons.org/licenses/by/4.0/), which permits unrestricted use, distribution, and reproduction in any medium, provided you give appropriate credit to the original author(s) and the source, provide a link to the Creative Commons license, and indicate if changes were made.

\section{References}

1. Akiyoshi $\mathrm{T}$ et al (2011) Incidence of and risk factors for anastomotic leakage after laparoscopic anterior resection with intracorporeal rectal transection and double-stapling technique anastomosis for rectal cancer. Am J Surg 202(3):259-264

2. Ito $M$ et al (2008) Relationship between multiple numbers of stapler firings during rectal division and anastomotic leakage after laparoscopic rectal resection. Int $J$ Colorectal Dis 23(7):703-707
3. Kim JS et al (2009) Risk factors for anastomotic leakage after laparoscopic intracorporeal colorectal anastomosis with a double stapling technique. J Am Coll Surg 209(6):694-701

4. Park JS et al (2013) Multicenter analysis of risk factors for anastomotic leakage after laparoscopic rectal cancer excision: the Korean laparoscopic colorectal surgery study group. Ann Surg 257(4):665-771

5. Kawada K et al (2014) Risk factors for anastomotic leakage after laparoscopic low anterior resection with DST anastomosis. Surg Endosc 28(10):2988-2995

6. Kim SH et al (2006) Laparoscopic resection for rectal cancer: a prospective analysis of thirty-month follow-up outcomes in 312 patients. Surg Endosc 20(8):1197-1202

7. Masoomi $\mathrm{H}$ et al (2013) Compression anastomosis ring device in colorectal anastomosis: a review of 1,180 patients. Am J Surg 205(4):447-451

8. Rahbari NN et al (2010) Definition and grading of anastomotic leakage following anterior resection of the rectum: a proposal by the International Study Group of Rectal Cancer. Surgery 147(3):339-351

9. Caulfield H, Hyman NH (2013) Anastomotic leak after low anterior resection: a spectrum of clinical entities. JAMA Surg 148(2): 177-182

10. Senn N (1893) Enterorrhaphy; it's history, technique and present status. JAMA 21:21

11. Mortensen NJ. Intestinal Anastomosis. In: ACS surgery: principles and practice. 5. Gastrointestinal Tract and Abdomen, 2008

12. Docherty JG et al (1995) Comparison of manually constructed and stapled anastomoses in colorectal surgery. West of Scotland and Highland Anastomosis Study Group. Ann Surg 221(2):176-184

13. Yamamoto $\mathrm{S}$ et al (2012) Risk factors for anastomotic leakage after laparoscopic surgery for rectal cancer using a stapling technique. Surg Laparosc Endosc Percutan Tech 22(3):239-243

14. Makela JT, Kiviniemi H, Laitinen S (2003) Risk factors for anastomotic leakage after left-sided colorectal resection with rectal anastomosis. Dis Colon Rectum 46(5):653-660

15. Akiyoshi T et al (2009) Safety of laparoscopic total mesorectal excision for low rectal cancer with preoperative chemoradiation therapy. J Gastrointest Surg 13(3):521-525

16. Scheidbach $\mathrm{H}$ et al (2002) Laparoscopic abdominoperineal resection and anterior resection with curative intent for carcinoma of the rectum. Surg Endosc 16(1):7-13

17. Yeh CY et al (2005) Pelvic drainage and other risk factors for leakage after elective anterior resection in rectal cancer patients: a prospective study of 978 patients. Ann Surg 241(1):9-13

18. Dauser B et al (2013) Anastomotic leakage after low anterior resection for rectal cancer: comparison of stapled versus compression anastomosis. Langenbecks Arch Surg 398(7):957-964

19. WHO. Obesity and overweight-Fact sheet N311. http://www. who.int/mediacentre/factsheets/fs311/en/. Accessed Aug 2014

20. Seidell JC, Flegal KM (1997) Assessing obesity: classification and epidemiology. Br Med Bull 53(2):238-252

21. D'Hoore A et al (2015) COMPRES: a prospective postmarketing evaluation of the compression anastomosis ring CAR 27()/ ColonRing(). Colorectal Dis 17(6):522-529

22. Matthiessen P et al (2004) Risk factors for anastomotic leakage after anterior resection of the rectum. Colorectal Dis 6(6):462-469

23. Levack M et al (2011) Laparoscopy decreases anastomotic leak rate in sigmoid colectomy for diverticulitis. Arch Surg 146(2):207-210

24. Matthiessen P et al (2007) Defunctioning stoma reduces symptomatic anastomotic leakage after low anterior resection of the rectum for cancer: a randomized multicenter trial. Ann Surg 246(2):207-214 
25. Dulucq JL et al (2005) Laparoscopic rectal resection with anal sphincter preservation for rectal cancer: long-term outcome. Surg Endosc 19(11):1468-1474

26. Jacobs M, Verdeja JC, Goldstein HS (1991) Minimally invasive colon resection (laparoscopic colectomy). Surg Laparosc Endosc 1(3): 144-150

27. Feliciotti F et al (2003) Long-term results of laparoscopic versus open resections for rectal cancer for 124 unselected patients. Surg Endosc 17(10):1530-1535

28. Zhang FW et al (2014) Laparoscopic versus open surgery for rectal cancer: a systematic review and meta-analysis of randomized controlled trials. Asian Pac J Cancer Prev 15(22):9985-9996
29. Leroy J et al (2004) Laparoscopic total mesorectal excision (TME) for rectal cancer surgery: long-term outcomes. Surg Endosc 18(2):281-289

30. Nussbaum DP et al (2015) Laparoscopic versus open low anterior resection for rectal cancer: results from the national cancer data base. J Gastrointest Surg. 19(1):124-131 discussion 131-132

31. Zhou ZG et al (2004) Laparoscopic versus open total mesorectal excision with anal sphincter preservation for low rectal cancer. Surg Endosc 18(8):1211-1215

32. Lacy AM et al (2002) Laparoscopy-assisted colectomy versus open colectomy for treatment of non-metastatic colon cancer: a randomised trial. Lancet 359(9325):2224-2229 